\title{
Peran Brand Likeability dalam Memoderasi Hubungan antara Ekuitas Merek dan Kinerja Merek pada Bank Syariah
}

\author{
Ziyan Sakinah Alisa', Egi Arvian Firmansyah ${ }^{2 *}$ \\ Universitas Padjadjaran ${ }^{1,2}$ \\ *egi.firmansyah@unpad.ac.id
}

\begin{abstract}
This research aims to find the effect of brand equity towards brand performance moderated by brand likeability, where brand equity is explained by it's four dimensions, which are brand awareness, brand association, perceived quality and brand loyalty. Using quantitative approach, this research uses questionnaire method with Likert scale and specifically targets customers of Bank Syariah Mandiri. The amount of sample being used in this research is 166 respondents. Before the questionnaire was opened to the public, it was tested by the first 30 respondents, consisting lecturer and students of Islamic Economics major in Padjadjaran University. The obtained data then processed using Structural Equation Modelling (SEM) on AMOS software. The results found that brand equity moderated by brand likeability has a significant effect on brand performance. In addition, among the four dimensions of brand equity, only brand awareness has a significant relationship with brand performance.
\end{abstract}

Keywords: Brand Equity, Brand Performance, Brand Likeability, Bank Syariah Mandiri, Structural Equation Model

\begin{abstract}
Abstrak
Penelitian ini bertujuan untuk mencari tahu apakah ada pengaruh yang signifikan antara ekuitas merek dan kinerja merek jika dimoderasi dengan variabel brand likeability, dimana ekuitas merek dijelaskan dengan empat dimensinya, yaitu kesadaran merek, asosiasi merek, kualitas yang dipersepsikan dan loyalitas merek. Penelitian ini bersifat kuantitatif dan menggunakan metode kuesioner dengan skala Likert yang ditujukan kepada nasabah Bank Syariah Mandiri. Jumlah sampel yang digunakan adalah 166 responden. Sebelum disebarkan secara umum, kuesioner telah diuji validitas, reliabilitas dan model fitnya dengan software SPSS dan AMOS. kuesioner juga terlebih dahulu diberikan kepada 30 responden yang terdiri dari dosen dan mahasiswa jurusan Ekonomi Islam di Fakultas Ekonomi dan Bisnis Universitas Padjadjaran. Kemudian, data yang didapatkan dari keseluruhan kuesioner diolah menggunakan Structural Equation Modelling (SEM) pada software AMOS. Hasilnya ditemukan bahwa ekuitas merek dengan dimoderasi oleh variabel brand likeability memiliki pengaruh yang signifikan terhadap kinerja merek. Selain itu, di antara empat dimensi dari ekuitas merek, hanya kesadaran merek yang memiliki hubungan yang signifikan dengan kinerja merek.
\end{abstract}

Kata Kunci: Ekuitas Merek, Kinerja Merek, Brand Likeability, Bank Syariah Mandiri, Structural Equation Model 


\section{PENDAHULUAN}

Evaluasi merupakan salah satu fungsi dari manajemen yang dilakukan oleh setiap perusahaan pada akhir periode tertentu. Banyak cara yang dilakukan untuk mengevaluasi kinerja dari suatu perusahaan, seperti melalui balance score card, tingkat kepuasan pelanggan dan kinerja merek. Namun dari kedua bentuk evaluasi perusahaan tersebut, tidak terdapat evaluasi yang berkaitan dengan merek. Padahal, Keller (2013) menyatakan bahwa merek bertujuan untuk membedakan suatu produk yang dihasilkan perusahaan dari perusahaan yang lainnya. Chirani et. al. (2012) juga menyatakan bahwa merek memiliki peran penting dalam menentukan kesuksesan dari sebuah perusahaan dengan menciptakan keunggulan bersaing melalui hal-hal yang tidak berkaitan dengan produk. Chirani et. al. (2012) juga menambahkan bahwa memahami perbedaan dari suatu produk melalui mereknya telah banyak memberi manfaat pada perusahaan, seperti pemasukan yang konsisten selama bertahun-tahun, peningkatan arus kas dan kemampuan untuk bertahan dari persaingan.

Untuk meningkatkan kinerja merek tersebut, Aaker (1991) mengusulkan sebuah konsep pemasaran yang disebut ekuitas merek. Aaker (1991) juga menjelaskan bahwa ekuitas merek adalah seperangkat aset dari suatu merek dan juga liabilitas yang berkaitan dengan sebuah merek, yaitu namanya dan simbolnya, yang akan menambah atau mengurangi nilai yang diberikan oleh suatu produk atau jasa terhadap sebuah perusahaan dan/atau konsumen dari perusahaan tersebut. Ekuitas merek yang positif atau baik dapat menciptakan afeksi dari konsumen dan dalam jangka panjang akan meningkatkan loyalitas dari konsumen (Aaker, 1991).

Kemudian Keller (2012) juga memiliki pemikiran tersendiri mengenai konsep ini yang diberi nama Customer Based Brand Equity, dimana pengukuran ekuitas merek dilakukan melalui perspektif konsumen. Karena menurut Kotler dan Keller (2016) pada model Consumer Behavior, konsumen dipengaruhi beberapa faktor yang akan mempengaruhi keputusannya untuk membeli atau menggunakan suatu produk atau jasa. Salah satu dari faktor tersebut adalah persepsi, Kotler dan Keller (2016) juga menjelaskan bahwa dalam dunia pemasaran, persepsi konsumen adalah sesuatu yang lebih penting dari realita karena persepsi konsumen adalah sesuatu yang dilihat, dirasa, didengar dan diterjemahkan oleh konsumen menjadi sebuah pengetahuan atas suatu produk yang dipasarkan. Seperti yang telah dilakukan Narteh (2018) yang mengukur ekuitas merek berdasarkan persepsi konsumennya dan melihat pengaruhnya terhadap kinerja merek.

Dalam penelitian terdahulu yang dilakukan oleh Narteh (2018), telah dibuktikan bahwa ekuitas merek memiliki dampak yang signifikan dan baik terhadap kinerja keuangan suatu perusahaan. Narteh (2018) juga menyatakan bahwa hubungan antara ekuitas merek dan kinerja keuangan dapat dimoderasi dengan brand likeability. Selain itu, beberapa penelitian terdahulu lainnya yang berkaitan dengan ekuitas merek atau brand likeability 
Peran Brand Likeability dalam Memoderasi Hubungan antara Ekuitas Merek dan Kinerja Merek pada Bank Syariah

adalah Yang, et. al. (2019), Chirani, et. al. (2012), Quan (2006), Nguyen (2013) dan Rahman, et. al. (2019). Nguyen (2013) mendefinisikan brand likeability sebagai ketertarikan yang dirasakan pelanggan terhadap suatu merek. Meski penelitian mengenai ekuitas merek dan CBBE telah menjadi topik yang tidak asing untuk diteliti, namun variabel brand likeability inilah yang masih terbilang sulit untuk ditemukan penelitiannya yang berkaitan dengan ekuitas merek. Menurut Benjamin dan Vithala R. (2005) dalam Chirani. et. al. (2012), penelitian mengenai ekuitas merek yang didasari oleh perspektif konsumen pada umumnya berkaitan dengan data tentang pikiran, perasaan dan perilaku dari seorang konsumen terhadap sebuah merek.

Pada konsep awal yang dicetuskan oleh Aaker (1991), ekuitas merek memiliki lima dimensi yaitu loyalitas merek, kesadaran merek, kualitas yang dipersepsikan, asosiasi merek dan aset tambahan lainnya. Dalam penelitian ini akan digunakan empat dimensi yang berbasis konsumen.

Penelitian terdahulu yang dilakukan oleh Narteh (2018) menggunakan nasabah bank konvensional di Ghana sebagai respondennya, sedangkan pada beberapa penelitian terdahulu yang menggunakan variabel ekuitas merek dan brand likeability, tidak terdapat satupun penelitian, baik yang berasal dari Indonesia maupun yang berasal dari luar Indonesia, yang menggunakan nasabah bank syariah sebagai objek penelitiannya.

Dari uraian tersebut, perlu diadakannya penelitian mengenai pengaruh ekuitas merek terhadap kinerja keuangan dengan Brand Likeability sebagai variabel moderasi dengan studi kasus perbankan syariah di Indonesia khususnya pada Bank Syariah Mandiri. Peneliti memilih nasabah Bank Syariah Mandiri karena Bank Syariah Mandiri adalah bank syariah di Indonesia yang dimiliki oleh negara, serta berdasarkan laporan tahunan Bank Syariah Mandiri tahun 2018, Bank Syariah Mandiri memiliki aset, pembiayaan, laba dan ekuitas terbesar, juga jaringan terluas di antara semua bank syariah di Indonesia (0JK,2019).

\section{KAJIAN LITERATUR \\ Teori Perilaku Konsumen}

Perilaku konsumen merupakan interaksi antara pemikiran, perasaan, perilaku dan lingkungan dimana terjadi pertukaran dalam berbagai aspek kehidupan manusia (Peter \& Olson, 2010). Dari pengertian tersebut, Peter dan Olson (2010) membangun kerangka untuk menganalisisi perilaku konsumen. Kerangka tersebut terdiri dari tiga elemen, yaitu : pemikiran dan perasaan, perilaku serta lingkungan. Dalam penelitian ini, elemen brand likeability merupakan bagian dari perasaan konsumen, sedangkan kinerja merek merupakan bagian dari pemikiran konsumen. Brand likeability mengindikasikan ikatan emosional antara konsumen dan produk, sedangkan kinerja merek merupakan cara konsumen untuk memberikan interpretasi terhadap merek. Penelitian ini juga memasukkan ekuitas merek, sebagai bagian dari elemen strategi pemasaran, yang menurut Peter dan Olson (2010) memiliki interaksi dengan pemikiran dan perasaan konsumen. 


\section{Merek dalam Manajemen Pemasaran}

Pemasaran menurut (Kotler dan Keller, 2016) adalah bagaimana mengidentifikasi dan memenuhi kebutuhan individu serta kebutuhan masyarakat secara umum. Kemudian menurut American Marketing Association (AMA) dalam Kotler \& Keller (2016) menyatakan bahwa pemasaran adalah seperangkat kegiatan dari suatu institusi atau seperangkat proses untuk membuat, mengkomunikasikan, menyampaikan dan menukar penawaran yang memiliki nilai bagi para konsumen, klien dan masyarakat secara keseluruhan. McCarthy yang dijelaskan dalam Kotler \& Keller (2016) mengelompokkan kegiatan-kegiatan pemasaran ini ke dalam bauran pemasaran yang terdiri dari 4P, yaitu; produk (product), promosi (promotion), harga (price) dan tempat (place). Yang mana pada penelitian ini akan berfokus pada kegiatan pada kelompok produk yang berkaitan dengan merek (brand).

\section{Ekuitas Merek (Brand Equity)}

Ekuitas merek (brand equity) adalah perbedaan dalam suatu hasil yang diperoleh dengan cara memberikan nilai tambah pada suatu produk sebagai bagian dari aktivitas pemasaran dari suatu merek (Keller, 2012). Nilai dari suatu merek dapat digunakan untuk memberikan keuntungan bagi perusahaan dalam bentuk hasil yang lebih besar atau biaya yang lebih kecil (Keller, 2003). Sementara Aaker (1991) mendefinisikan ekuitas merek sebagai sebuah aset dan liabilitas yang berkaitan dengan suatu merek, yang mampu menambah ataupun mengurangi nilai yang diberikan oleh suatu produk atau jasa kepada perusahaan dan konsumennya. Dalam model tersebut, Aaker (1991) juga mengelompokkan aset dan liabilitas tersebut menjadi lima dimensi, yaitu loyalitas merek, kesadaran nama, kualitas yang dipersepsikan, asosiasi merek dan aset tambahan lainnya.

\section{Bank Syariah}

Perbankan syariah di Indonesia telah diatur dalam Undang-Undang no 21 tahun 2008 tentang. Undang-undang tersebut mendefinisikan bank syariah sebagai bank yang menjalankan kegiatan usahanya berdasarkan prinsip syariah. Prinsip syariah yang dimaksud adalah kegiatan usaha yang tidak mengandung unsur-unsur Riba, Judi (Maisir), Ketidakpastian (Gharar), Haram dan Zalim. Berbeda dengan bank konvensional yang bergantung pada bunga sebagai prinsip utama dari keuntungannya, bank syariah pada umumnya dikenal sebagai bank yang kegiatan finansialnya tidak berkaitan dengan tingkat bunga (Alden, 2015).

Undang-undang no 21 tahun 2008 juga mewajibkan bagi bank Syariah untuk membentuk Dewan Pengawas Syariah atas rekomendasi dari Majelis Ulama Indonesia, sementara bank konvensional tidak diawasi oleh Dewan Pengawas Syariah. Menurut (Tanjung, 2015) bank syariah juga hanya boleh menyalurkan investasinya pada perusahaan yang tidak bertentangan dengan syariah, namun hal ini tidak berlaku bagi bank konvensional. 
Peran Brand Likeability dalam Memoderasi Hubungan antara Ekuitas Merek dan Kinerja Merek pada Bank Syariah

\section{Kinerja Merek (Brand Performance)}

Aaker (1996) menyatakan bahwa kinerja merek dapat diukur melalui beberapa faktor seperti harga pasar, market share dan sebaran distribusi. Dalam penelitian yang dilakukan oleh Chirani, et. al (2012), dapat diperkirakan bahwa beberapa aspek dari ekuitas merek, seperti loyalitas merek dan kesadaran merek, mampu meningkatkan kinerja merek.

\section{Asosiasi Merek (Brand Association)}

Asosiasi merek (brand association) adalah segala sesuatu yang terhubung dalam ingatan konsumen dengan suatu merek. Asosiasi juga memiliki tingkat kekuatan. Ikatan antara pelanggan dengan suatu merek akan lebih kuat ketika didasarkan pada banyak pengalaman atau interaksi (Aaker, 1991). Kotler dan Keller (2016) menyatakan bahwa asosiasi merek terdiri dari segala pikiran, perasaan, persepsi, citra, pengalaman, kepercayaan dan perilaku dari seorang pembeli yang berkaitan dengan suatu merek tertentu. Asosiasi merek juga telah terbukti memiliki pengaruh terhadap kinerja merek atau kinerja perusahaan (Aydin \& Ulengin, 2016; Mohan \& Sequiera, 2016). Dari penjelasan berikut, hipotesis yang berkaitan dengan asosiasi merek sebagai dimensi dari ekuitas merek adalah sebagai berikut:

H1: Asosiasi merek berpengaruh secara signifikan terhadap kinerja merek.

\section{Kesadaran Merek (Brand Awareness)}

Kesadaran merek (brand awareness) adalah kemampuan pembeli potensial untuk mengenali atau mengingat bahwa suatu merek adalah anggota dari kategori produk tertentu (Aaker, 1991). Menurut Keller (2012), kesadaran merek terdiri dari brand recognition dan brand recall performance; brand recognition adalah kemampuan pelanggan untuk mengenali sebuah merek di antara merek-merek lainnya. Sementara brand recall adalah kemampuan pelanggan untuk mengingat sebuah merek ketika produk sebuah kategori dari produk tersebut ditanyakan. Kesadaran merek juga telah terbukti mempengaruhi kinerja merek atau kinerja perusahaan (Aydin \& Ulengin, 2016; Baldauf et al., 2003; Buzdar et al., 2016). Dari penjelasan berikut, hipotesis yang berkaitan dengan kesadaran merek sebagai dimensi dari ekuitas merek adalah sebagai berikut:

H2: Kesadaran merek berpengaruh secara signifikan terhadap kinerja merek.

\section{Kualitas yang Dipersepsikan (Perceived Quality)}

Kualitas yang dipersepsikan (perceived quality) adalah persepsi pelanggan tentang kualitas keseluruhan atau keunggulan suatu produk atau layanan sehubungan dengan tujuan tertentu yang diinginkan oleh pelanggan. Persepsi kualitas tidak selalu dapat ditentukan secara objektif, karena sebagian darinya adalah persepsi pelanggan. Dengan kata lain, setiap pelanggan memiliki penilaian tentang apa yang penting bagi pelanggan tersebut dan setiap pelanggan sangat berbeda dalam kepribadian, 
kebutuhan, dan preferensi mereka (Aaker, 1991). Kualitas yang dipersepsikan telah terbukti mempengaruhi kinerja merek atau kinerja perusahaan (Aydin \& Ulengin, 2016; Baldauf et al., 2003; Buzdar et al., 2016, Kim \& Kim, 2005; Mohan \& Sequiera, 2016). Dari penjelasan berikut, hipotesis yang berkaitan dengan kualitas yang diperepsikan sebagai dimensi dari ekuitas merek adalah sebagai berikut:

H3: Kualitas yang dipersepsikan berpengaruh secara signifikan terhadap kinerja merek.

\section{Loyalitas Merek (Brand Loyalty)}

Aaker (1991) mendefinisikan loyalitas merek (brand loyalty) yang berdasar pada pelanggan adalah inti dari ekuitas merek karena loyalitas merek merupakan tingkat keterikatan yang dimiliki pelanggan terhadap suatu merek. Dengan kata lain, loyalitas merek menunjukkan seberapa besar kemungkinan pelanggan untuk beralih ke merek lain, terutama ketika merek itu melakukan perubahan, baik dalam harga atau dalam fitur produk. Kotler dan Keller (2016) juga menjelaskan bahwa loyalitas merek menciptakan kestabilan permintaan akan suatu perusahaan dan menciptakan halangan bagi perusahaan baru untuk masuk ke pasar. Dengan meningkatnya loyalitas merek, kemungkinan pelanggan beralih ke merek lain akan berkurang. Ini adalah salah satu indikator ekuitas merek yang terbukti terkait dengan laba di masa depan, karena loyalitas merek secara langsung diterjemahkan menjadi penjualan di masa depan. Hal tersebut juga telah terbukti mempengaruhi kinerja merek atau perusahaan (Baldauf et al., 2003; Buzdar et al., 2016, Kim \& Kim, 2005; Mohan \& Sequiera, 2016). Dari penjelasan berikut, hipotesis yang berkaitan dengan loyalitas merek sebagai dimensi dari ekuitas merek adalah sebagai berikut:

H4: Loyalitas merek berpengaruh secara signifikan terhadap kinerja merek.

\section{Brand Likeability}

Menurut penelitian Nguyen, et. al (2013), brand likeability adalah strategi merek yang bertujuan untuk memengaruhi persepsi konsumen secara positif serta meningkatkan daya tarik dari suatu merek. Untuk mencapai hal tersebut, Nguyen, et. al. (2013) juga menyatakan beberapa komponen atau kata kunci dari brand likeability seperti daya tarik, integritas, pelayanan yang baik, keterkaitan atau cinta, komunikasi dan kenyamanan yang tercipta antara perusahaan dan pelanggannya. Secara singkat, Nguyen, et. al. (2013) mendefinisikan brand likeability sebagai ketertarikan yang dirasakan pelanggan terhadap suatu merek. Brand likeability ini masih dibilang cukup jarang ditemukan dalam penelitian ilmiah, namun Narteh (2018) telah membuktikan adanya pengaruh antara ekuitas merek yang dimoderasi brand likeability terhadap kinerja merek. Dari penjelasan berikut, hipotesis yang berkaitan dengan brand likeability adalah sebagai berikut: H5: Ekuitas merek berpengaruh secara signifikan terhadap kinerja merek dengan brand likeability sebagai moderasi. 

dan Kinerja Merek pada Bank Syariah

\section{METODE PENELITIAN}

Penelitian ini merupakan penelitian bersifat kuantitatif dengan metode kuesioner dengan skala Likert, selanjutnya diolah menggunakan metode Structural Equation Modelling (SEM). SEM adalah salah satu dari metode statistik yang menggunakan pendekatan confirmatory untuk menganalisis sebuah teori terstruktur yang berkaitan dengan sebuah fenomena (Byrne, 2016).

Populasi dalam penelitian ini adalah nasabah Bank Syariah Mandiri. Metode pemilihan sampel dalam penelitian ini menggunakan Non-probability sampling dengan teknik purposive sampling. Kriteria responden yang telah ditentukan adalah nasabah Bank Syariah Mandiri yang masih memiliki rekening aktif.

Untuk jumlah sampel yang dibutuhkan dalam penggunaan Structural Equation Model (SEM), belum ada kesepakatan jumlah minimum yang dibutuhkan. Namun salah satu pertimbangan yang dapat membantu penentuan jumlah sampel ini adalah secara umum jumlah sampel yang dibutuhkan oleh model SEM yang memiliki variabel laten sampai dengan lima variabel, serta setiap variabelnya dijelaskan oleh tiga atau lebih indikator, maka jumlah sampel kisaran 100-150 data sudah dianggap memadai (Santoso, 2018).

\section{PEMBAHASAN}

Hasil dari penelitian ini didapatkan 166 responden dengan karakteristik jenis kelamin mayoritas perempuan, rentang usia mayoritas 2129 tahun, pendidikan terakhir mayoritas SMA, pekerjaan mayoritas pelajar/mahasiswa, hubungan dengan bank mayoritas penabung serta jangka waktu menjadi nasabah bank mayoritas 1-2 tahun. Kemudian untuk pertanyaan tambahan tentang pengetahuan atau ingatan responden tentang logo dan warna BSM. Mayoritas dapat mengingat dengan benar logo dan warna dari BSM.

Sebelum disebar ke umum, kuisioner terlebih dahulu disebar ke 30 orang yang terdiri dari mahasiswa dan dosen FEB Unpad. Kemudian hasil uji validitas dan reliabilitas menunjukkan bahwa semua item kuisioner valid dan reliabel. Kemudian pengujian model fit, validitas diskriminan, validitas konvergen dan Composite Reliability juga dilakukan dan didapatkan hasil seperti berikut: 
Tabel 1

Hasil Model Fit

\begin{tabular}{|c|c|c|c|}
\hline Kriteria & Nilai Acuan & Nilai dari model & Kesimpulan \\
\hline$p$-value & $\geq 0,05$ & 0,000 & Belum fit \\
\hline $\mathrm{CMIN} / \mathrm{df}$ & $\leq 2,00$ & 1,562 & Sudah Fit \\
\hline RMSEA & $\leq 0,08$ & 0,058 & Sudah Fit \\
\hline GFI & Mendekati 1 & 0,897 & Sudah Fit \\
\hline CFI & Mendekati 1 & 0,961 & Sudah Fit \\
\hline RMR & Mendekati 0 & 0,30 & Sudah Fit \\
\hline $\mathrm{AIC}$ & $\begin{array}{l}\text { AIC pada default model } \\
\text { harus lebih kecil dari AIC } \\
\text { pada saturated model dan } \\
\text { independence model }\end{array}$ & $\begin{array}{l}260,811(\text { default })< \\
306(\text { saturated })< \\
1656,577 \\
\text { (independence) }\end{array}$ & Sudah Fit \\
\hline ECVI & $\begin{array}{l}\text { ECVI pada default model } \\
\text { harus lebih kecil dari ECVI } \\
\text { pada saturated model dan } \\
\text { independence model }\end{array}$ & $\begin{array}{l}1,581(\text { default })< \\
1,855(\text { saturated })< \\
10,040 \\
\text { (independence) }\end{array}$ & Sudah Fit \\
\hline
\end{tabular}

Sumber: Data diolah 2020

Tabel 2

Nilai Validitas Konvergen

\begin{tabular}{lllll}
\hline \multicolumn{1}{c}{ Kriteria } & Variabel & \multicolumn{1}{c}{$\begin{array}{c}\text { Nilai } \\
\text { Acuan }\end{array}$} & $\begin{array}{c}\text { Nilai } \\
\text { Model }\end{array}$ & Kesimpulan \\
\hline Factor & AS $\rightarrow$ AS1 & $\geq 0,50$ & 0,791 & Valid \\
Loadings & AS $\rightarrow$ AS2 & $\geq 0,50$ & 0,771 & Valid \\
& BA $\rightarrow$ BA1 & $\geq 0,50$ & 0,573 & Valid \\
& BA $\rightarrow$ BA5 & $\geq 0,50$ & 0,868 & Valid \\
& PQ $\rightarrow$ PQ2 & $\geq 0,50$ & 0,687 & Valid \\
& PQ $\rightarrow$ PQ3 & $\geq 0,50$ & 0,779 & Valid \\
& LO $\rightarrow$ LO1 & $\geq 0,50$ & 0,852 & Valid \\
& LO $\rightarrow$ LO2 & $\geq 0,50$ & 0,731 & Valid \\
& LO $\rightarrow$ LO3 & $\geq 0,50$ & 0,875 & Valid \\
& LO $\rightarrow$ LO4 & $\geq 0,50$ & 0,759 & Valid \\
\hline
\end{tabular}


Peran Brand Likeability dalam Memoderasi Hubungan antara Ekuitas Merek dan Kinerja Merek pada Bank Syariah

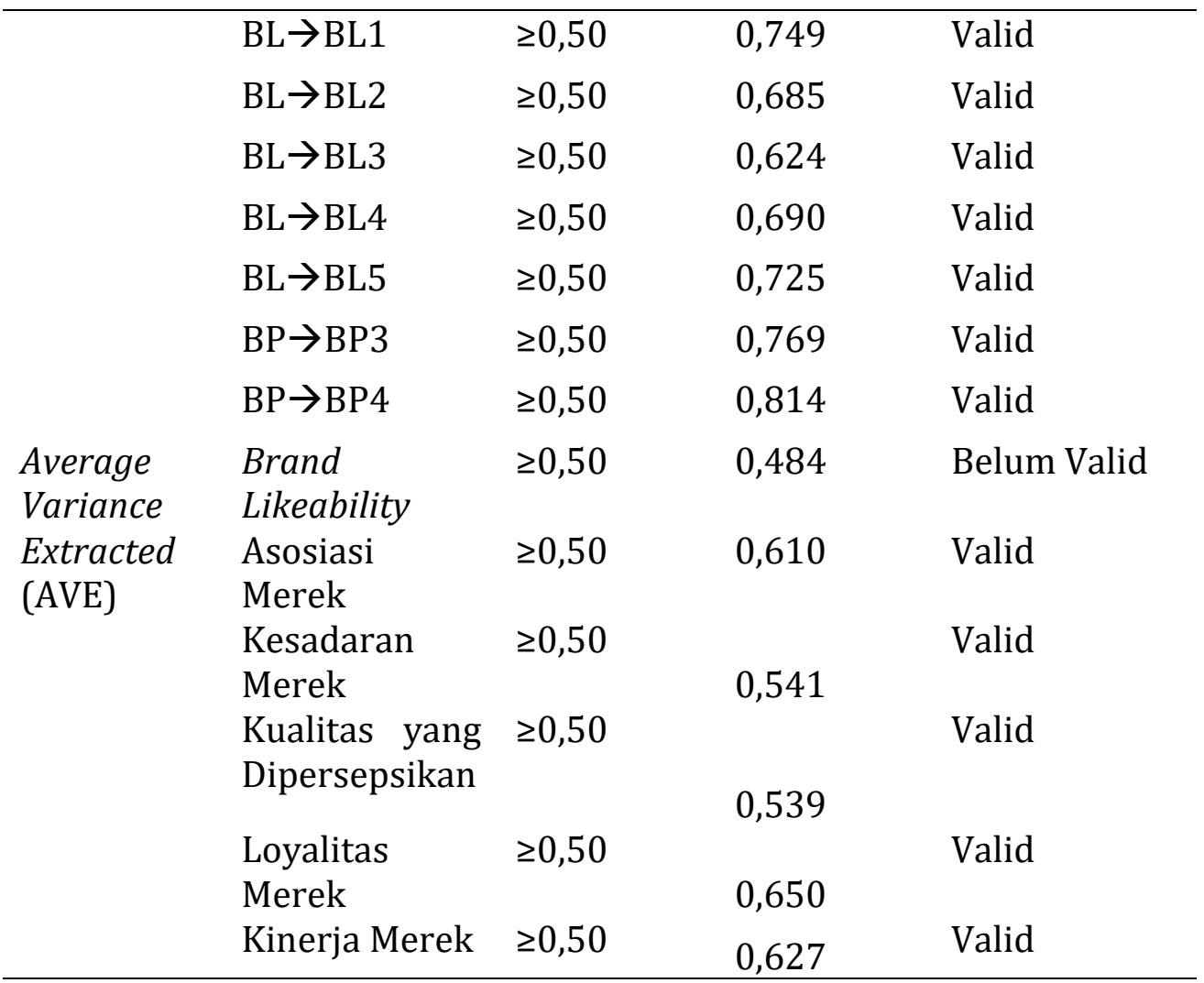

Sumber: Santoso (2017), Wijaya (2006) dan pengolahan data kuesioner.

Tabel 3

Nilai Validitas Diskriminan

\begin{tabular}{lllllll}
\hline Variabel & $B L$ & AS & BA & PQ & LO & BP \\
\hline$B L$ & $\mathbf{0 , 6 9 6}$ & & & & & \\
AS & 0,780 & $\mathbf{0 , 7 8 1}$ & & & & \\
BA & 0,767 & 0,626 & $\mathbf{0 , 7 3 5}$ & & & \\
PQ & 0,877 & 0,823 & 0,544 & $\mathbf{0 , 7 3 4}$ & & \\
LO & 0,764 & 0,633 & 0,626 & 0,758 & $\mathbf{0 , 8 0 7}$ & \\
BP & 0,786 & 0,520 & 0,635 & 0,668 & 0,610 & $\mathbf{0 , 7 9 2}$ \\
\hline
\end{tabular}

Tabel 4

Nilai Composite Reliability

\begin{tabular}{llll}
\hline \multicolumn{1}{c}{ Variabel } & Nilai Acuan & Nilai Model & Kesimpulan \\
\hline Brand Likeability & $>0,7$ & 0,824 & Reliabel \\
Asosiasi Merek & $>0,7$ & 0,758 & Reliabel \\
Kesadaran Merek & $>0,7$ & 0,693 & Reliabel \\
Kualitas yang & $>0,7$ & 0,700 & Reliabel \\
\hline
\end{tabular}




\begin{tabular}{llll}
\hline Dipersepsikan & & & \\
Loyalitas Merek & $>0,7$ & 0,881 & Reliabel \\
Kinerja Merek & $>0,7$ & 0,771 & Reliabel \\
\hline
\end{tabular}

Sumber: Hair, et. al (2014) dan pengolahan data kuesioner.

Kemudian dari pengujian model struktural didapatkan hasil sebagai berikut:

Tabel 5

Hasil Uji Model Struktural

\begin{tabular}{|c|c|c|c|}
\hline No & Hipotesis & P-Value & Keterangan \\
\hline H1 & $\begin{array}{l}\text { Asosiasi merek berpengaruh secara } \\
\text { signifikan terhadap kinerja merek }\end{array}$ & 0,247 & $\begin{array}{l}\text { Tidak signifikan (H0 } \\
\text { diterima) }\end{array}$ \\
\hline $\mathrm{H} 2$ & $\begin{array}{l}\text { Kesadaran merek berpengaruh } \\
\text { secara signifikan terhadap kinerja } \\
\text { merek }\end{array}$ & 0,008 & Signifikan (H0 ditolak) \\
\hline H3 & $\begin{array}{l}\text { Kualitas yang dipersepsikan } \\
\text { berpengaruh secara signifikan } \\
\text { terhadap kinerja merek }\end{array}$ & 0,076 & $\begin{array}{l}\text { Tidak signifikan (H0 } \\
\text { diterima) }\end{array}$ \\
\hline $\mathrm{H} 4$ & $\begin{array}{l}\text { Loyalitas merek berpengaruh } \\
\text { secara signifikan terhadap kinerja } \\
\text { merek }\end{array}$ & 0,947 & $\begin{array}{l}\text { Tidak signifikan (H0 } \\
\text { diterima) }\end{array}$ \\
\hline H5 & $\begin{array}{l}\text { Ekuitas merek yang dimoderasi } \\
\text { dengan brand likeability } \\
\text { berpengaruh secara signifikan } \\
\text { terhadap kinerja merek }\end{array}$ & 0,014 & Signifikan (H0 ditolak) \\
\hline
\end{tabular}

Sumber: pengolahan data (2020)

Hasil dari model struktural SEM menunjukkan bahwa di antara keempat dimensi ekuitas merek yang digunakan dalam penelitian ini, hanya kesadaran merek yang berpengaruh signifikan terhadap kinerja merek. Kemudian brand likeability juga terbukti berpengaruh signifikan dalam hubungan antara ekuitas merek dan kinerja merek. Hal ini sejalan dengan penelitian terdahulu yang dilakukan oleh Narteh (2018). Narteh (2018) juga menjelaskan bahwa jika seorang pelanggan atau nasabah tidak menyukai suatu merek, maka akan mempengaruhi niat untuk membeli produk dari merek tersebut. Sehingga dalam jangka panjang, akan mempengaruhi kinerja dari merek tersebut.

Namun dalam penelitian ini juga ditemukan bahwa asosiasi merek, loyalitas merek dan kualitas yang dipersepsikan tidak memiliki pengaruh yang signifikan terhadap kinerja merek. Hal ini berbeda dengan beberapa penelitian terdahulu, yaitu Narteh (2018) yang menemukan adanya pengaruh yang signifikan dari asosiasi merek, loyalitas merek dan kualitas 

dan Kinerja Merek pada Bank Syariah

yang dipersepsikan terhadap kinerja merek dari bank-bank retail di Ghana. Kemudian pada Quan (2006) ditemukan bahwa asosiasi merek dan loyalitas merek menunjukkan pengaruh yang signifikan terhadap kinerja merek di retail-retail. Serta pada penelitian oleh Yang et. al, (2019) ditemukan bahwa asosiasi merek memiliki pengaruh yang signifikan terhadap merek ponsel terbesar di Amerika Serikat.

Pada penelitian ini yang menggunakan studi kasus nasabah Bank Syariah Mandiri, variabel asosiasi merek yang berkaitan dengan bagaimana nasabah mengingat sebuah merek menunjukkan hasil pengaruh yang tidak signifikan terhadap kinerja merek. Secara umum, nasabah Bank Syariah Mandiri yang menjadi responden dari penelitian ini telah terbukti mengetahui dengan baik tentang merek Bank Syariah Mandiri, yaitu dengan mengasosiasikan merek Bank Syariah Mandiri dengan produk-produk yang ditawarkan, jasa yang diberikan, promosi cara hidup dan kesesuaian operasional Bank Syariah Mandiri dengan hukum dan prinsip Islam. Sehingga nasabah mampu melihat perbedaan atau nilai lebih yang diberikan oleh merek Bank Syariah Mandiri sebagai bank yang menjalankan kegiatan usahanya sesuai dengan prinsip Islam.

Namun hal tersebut masih belum mampu meningkatkan kinerja merek Bank Syariah Mandiri secara signifikan karena meski nasabah merasa Bank Syariah Mandiri sesuai dengan prinsip Islam, konsep dual banking atau adanya dua jenis bank yang digunakan di Indonesia, yaitu konvensional dan syariah, membuat nasabah secara langsung maupun tidak langsung, akan selalu menjadikan bank konvensional sebagai tolak ukur dalam keberhasilan atau kesuksesan dari suatu merek bank. Terlebih lagi bank konvensional yang sudah lebih dahulu berdiri dan mempertahankan eksistensinya di industri perbankan di Indonesia, maka akan membuat bank syariah secara keseluruhan disandingkan dengan bank konvensional.

Kemudian dari segi kualitas yang dipersepsikan, Bank Syariah Mandiri juga sudah memiliki kualitas yang tergolong cukup baik jika dibandingkan dengan bank-bank syariah lainnya. Terbukti dengan distribusi kantor cabang yang terbanyak se-Indonesia, serta kemudahan-kemudahan lainnya yang diberikan Bank Syariah Mandiri kepada nasabahnya agar merasa nyaman dalam bertransaksi dengan Bank Syariah Mandiri. Hal ini pun telah membawa Bank Syariah Mandiri pada penghargaan "The Best in Retail Service Banking" untuk kategori Bank Syariah yang diberikan oleh Majalah Tempo tahun 2019 (Situs Bank Syariah Mandiri, 2020).

Meskipun pelayanannya sudah cukup baik jika dibandingkan dengan bank-bank syariah lainnya, Bank Syariah Mandiri masih memiliki tantangan terbesar sebagai anak perusahaan dari bank konvensional yaitu Bank Mandiri, dimana Bank Mandiri, yang sudah lebih lama memiliki eksistensi di industri perbankan di Indonesia, memiliki standar operasional tersendiri yang telah diberlakukan selama bertahun-tahun lamanya. Namun menurut penelitian yang dilakukan oleh (Asnawi, Sukoco \& Fanani, 2019), nasabah bank syariah memiliki ekspektasi yang berbeda mengenai pelayanan jasa 
dalam perbankan jika dibandingkan dengan ekspektasi dari nasabah bank konvensional. Penelitian tersebut menemukan bahwa pada nasabah bank konvensional, kelengkapan fitur layanan dan tingkat responsif dari pegawai bank sangat diutamakan. Namun, nasabah bank syariah yang diteliti dalam (Asnawi, Sukoco \& Fanani, 2019) sebagian besar merasa bahwa yang diutamakan dari kualitas pelayanan di bank syariah adalah kejujuran, kepatuhan pada prinsip-prinsip Syariah dan kekuatan dari nilai-nilai Islam yang harus dikedepankan agar menjadi nilai pembeda dari suatu bank syariah terhadap bank konvensional.

Selanjutnya untuk variabel loyalitas merek, didapatkan hasil yang cukup baik dari tingkat loyalitas nasabah Bank Syariah Mandiri. Namun, hal tersebut tidak mampu memberikan pengaruh yang signifikan terhadap kinerja merek dari Bank Syariah Mandiri. Karena nasabah bank syariah di Indonesia secara keseluruhan masih beranggapan bahwa bank syariah adalah bank yang sifatnya sekunder, sementara bank konvensional masih dianggap sebagai bank yang lebih primer atau diutamakan. Ini artinya tingkat loyalitas nasabah bank syariah masih sangat rentan, terutama karena mudahnya nasabah berpindah dari perbankan syariah ke perbankan konvensional atas pertimbangan biaya atau keuntungan yang didapatkan dari produk bank syariah tersebut.

Selain itu, pada statistik deskriptif juga didapatkan nilai rata-rata dari asosiasi merek, kesadaran merek, kualitas yang dipersepsikan, loyalitas merek dan brand likeability menunjukkan nilai rata-rata yang cukup besar, yaitu antara 3,69-4,08, namun variabel kinerja merek (Y1) memiliki nilai rata-rata paling rendah yaitu sebesar 3,58. Hal ini menunjukkan nasabah Bank Syariah Mandiri sudah merasakan hasil dari ekuitas merek melalui indikator-indikator seperti kesadaran merek, asosiasi merek, loyalitas merek dan kualitas yang dipersepsikan, hanya saja nasabah belum melihat adanya kinerja merek yang signifikan oleh Bank Syariah Mandiri.

Pada realitanya, Bank Syariah Mandiri telah banyak melakukan upaya untuk meningkatkan ekuitas merek pada perspektif pelanggannya, seperti meluncurkan fitur pembukaan rekening secara daring, melaksanakan berbagai program corporate social responsibility (CSR) di sejumlah wilayah di Indonesia dan menyediakan 737 kantor layanan di seluruh Indonesia dengan akses lebih dari 196.000 jaringan ATM (Website Bank Syariah Mandiri, 2020). Terbukti, Bank Syariah Mandiri juga sudah mendapat berbagai penghargaan dalam hal pemasaran dan strategi merek, seperti penghargaan Indonesia Best Brand Award 2019 dalam kategori bank syariah dan Islamic Retail Bank Awards yang diberikan oleh Cambridge International Financial Advisory di tahun 2019 (Situs Bank Syariah Mandiri, 2020). Tetapi dalam hal kinerja merek, nasabah secara umum merasa bahwa belum terlihat adanya kinerja merek yang signifikan atau masih banyaknya nasabah yang mempersepsikan kinerja merek bank Syariah Mandiri yang belum mencapai level sangat baik (mean $=3,58)$. 
Peran Brand Likeability dalam Memoderasi Hubungan antara Ekuitas Merek dan Kinerja Merek pada Bank Syariah

\section{SIMPULAN}

Dari lima hipotesis yang diuji, hanya dua yang terbukti signifikan, artinya di antara 4 variabel yang merupakan komponen dari ekuitas merek, hanya kesadaran merek yang berpengaruh signifikan terhadap kinerja merek. Kemudian secara keseluruhan ekuitas merek yang dimoderasi brand likeability juga memiliki pengaruh yang signifikan terhadap kinerja merek. Maka disarankan bagi peneliti selanjutnya agar dapat memperluas subjek penelitian, seperti bank syariah atau konvensional lainnya, baik di Indonesia maupun di luar Indonesia, agar mendapatkan hasil yang lebih terdiversifikasi dan terbaharui.

\section{DAFTAR PUSTAKA}

Aaker, D. A. (1991). Managing Brand Equity.

Aaker, D. A. (1996). Measuring Brand Equity Across Products and Markets. California Management Review, 38(3), 102-120. https://doi.org/10.2307/41165845

Alhusin, S. (2003). Aplikasi Statistik dengan SPSS.

Asnawi, N., Sukoco, B., \& Fanani, M. (2019). The Role of Service Quality within Indonesian Customers' Satisfaction and Loyalty and its Impact on Islamic Banks. Journal of Islamic Marketing, 11(1), 192-212. https://doi.org/10.1108/JIMA-03-2017-0033

Aydin, G. \& Ulengin, B., (2015). Effect of Brand Equity on Firms' Financial Performance in Consumer Goods Industries. Journal of Business, Economics and Finance, 4(3), 331-350. https://doi.org/10.17261/Pressacademia.2105313056

Baldauf, A., Cravens, K.S. and Binder, G. (2003), "Performance consequences of brand equity management: evidence from organizations in the value chain". Journal of Product \& Brand Management, Vol. 12 No. 4, pp. 220236. https://doi.org/10.1108/10610420310485032

Buzdar, M. F., Janjua, S. Y. \& Khursid, M. A. (2016) Customer-based Brand Equity and Firms' Performance in the Telecom Industry. International Journal of Services and Operations Management, 25(3), 334. https://doi.org/10.1504/IJSOM/2016.079516

Byrne, B. M. (2016). Structural Equation Modeling with AMOS. Introduction to Structural Equation Modeling using IBM SPSS Statistics and AMOS. https://doi.org/10.4135/9781526402257.n4

Chaudhuri, A. \& Holbrook, M. (2001). The Chain of Effects from Brand Trust and Brand Affect to Brand Performance: The Role of Brand Loyalty. Journal of Marketing, 65(2), 81-93.

Chirani, E., Taleghani, M., \& Moghadam, N. E. (2012). Brand Performance and Brand Equity. Interdisciplinary Journal of Contemporary Research in Business, 3(9), 1033-1036.

Cooper, D. R., \& Schindler, P. S. (2014). Business Research Methods.

Hair, J. F., Babin, B. J., Anderson, R. E., \& Black, W. (2014). Multivariate Data 
Analysis.

Kahle, L. R., \& Malhotra, N. K. (1994). Marketing Research: An Applied Orientation. Journal of Marketing Research (Vol. 31). https://doi.org/10.2307/3151953

Keller, K. L. (2003). Understanding Brands, Branding and Brand Equity. Interactive Marketing, 5(1), 7-20. https://doi.org/10.1057/palgrave.im.4340213

Keller, K. L. (2013). Strategic Brand Management. https://doi.org/10.1057/bm.1998.36

Kim, H.B. \& Kim, W. G. (2005) The Relationship Between Brand Equity and Firms' Performance in Luxury Hotels and Chain Restaurants. Tourism Management, 26(4),

549-560. https://doi.org/10.1016/j.tourman.2004.03.010

Kotler, P., \& Keller, K. L. (2016). Marketing Management. Pearson. https://doi.org/10.4324/9780203357262

Mohan, C. B. \& Sequeira, A.H. (2016) The impact of customer-based brand equity on the operational performance of FMCG companies in India. IIMB Management Review, 28(1), 13-19. https://doi.org/10.1016/j.iimb.2015.11.002

Narteh, B. (2018). Brand Equity and Financial Performance: The Moderating Role of Brand Likeability. Marketing Intelligence and Planning, 36(3), 381-395. https://doi.org/10.1108/MIP-05-2017-0098

Nguyen, B., Melewar, T. C., \& Chen, J. (2013). A Framework of Brand Likeability: An Exploratory Study of Likeability in Firm-Level Brands. Journal of Strategic Marketing, 21(4), 368-390. https://doi.org/10.1080/0965254X.2013.790472

Oliveira-Castro, J., Foxall, G., James, V., et. al. (2008). Consumer-Based Brand Equity and Brand Performance. Service Industries Journal, 28(4), 445461.

Otoritas Jasa Keuangan. (2019). Statistik Perbankan Syariah.

Quan, T. H. M. (2006). Retailer's Perspective of Product Brand Equity: An Empirical Study of Vietnamese Independent Drink Stores. UNSW Australia. https://doi.org/10.33301/2011.13.02.05

Rahman, M., Rodriguez-Serrano, M., \& Lambkin, M. (2019). Brand Equity and Firm Performance: the Complementary Role of Corporate Social Responsibility. Journal of Brand Management, 26(6), 691-704. https://doi.org/10.1057/s41262-019-00155-9

Sakdiyah, K. (2019). Pengaruh Brand Equity Terhadap Proses Keputusan Nasabah Menabung Di Bank Syariah (Studi Pada Nasabah Bank Syariah Mandiri Dan Bni Syariah Di Dki Jakarta ). UIN Syarif Hidayatullah.

Santoso, S. (2018). Konsep Dasar dan Aplikasi SEM dengan AMOS 24.

Sekaran, U., \& Bougie, R. (2017). Metode Penelitian untuk Bisnis. 
Peran Brand Likeability dalam Memoderasi Hubungan antara Ekuitas Merek dan Kinerja Merek pada Bank Syariah

Sugiyono. (2010). Statistika untuk Penelitian.

Website Bank Syariah Mandiri. (2020). Retrieved from www.mandirisyariah.co.id

Wheelen, T. L., Hunger, J. D., Hoffman, A. N., \& Bamford, C. E. (2018). Strategic Management and Business Policy. Pearson.

Wijaya, T. (2009). Analisis Structural Equation Modeling Menggunakan AMOS.

Yang, D., Sonmez, M., Gonzalez, M., Liu, Y., \& Yoder, C. Y. (2019). ConsumerBased Brand Equity and Consumer-Based Brand Performance: Evidence from Smartphone Brands in the USA. Journal of Brand Management, 26(6), 717-732. https://doi.org/10.1057/s41262-019-00154-w

Zahrah, F. (2014). Strategi Membangun Brand Equity pada Bank Syariah Mandiri cabang Malang. UIN Maulana Malik Ibrahim.

Zikmund, W. G., \& Babin, B. J. (2009). Essentials of Marketing Research. 
Ziyan Sakinah Alisa, Egi Arvian Firmansyah

Halaman ini sengaja dikosongkan 